\title{
Comparison of clinical diagnoses and autopsy findings in 54 cases with lymphoid neoplasms
}

\author{
Lara Abraham $^{1} \cdot$ Hans Kreipe ${ }^{1} \cdot$ Kais Hussein ${ }^{1}$ \\ Received: 23 August 2018 / Accepted: 3 May 2019 / Published online: 21 May 2019 \\ (C) Springer-Verlag GmbH Germany, part of Springer Nature 2019
}

\begin{abstract}
There are few systematic analyses on autopsy findings of patients with lymphoid neoplasms. Autopsy cases with $(n=54)$ and without $(n=50)$ lymphoid neoplasms were compared for this study. Neoplasms found were B cell lymphomas $(n=30 / 54,56 \%)$, plasmacytomas $(n=15 / 54,28 \%)$, T cell lymphomas $(n=7 / 54,13 \%)$, Hodgkin lymphomas $(n=2 / 54,3 \%)$ and solid tumours $(n=7 / 54,13 \%)$. In the control group, $12 / 50(24 \%)$ cases had solid tumours. Autopsy alone identified the previously unknown lymphoid neoplasm in 10/54 (18\%) cases, whilst only 1/50 (2\%) previously unknown carcinoma was found in the control group. Cardiac/respiratory failure was the most frequent cause of death in the lymphoid neoplasm group $(n=35 / 54,65 \%)$ as well as in the control group $(n=36 / 50,72 \%)$. In $8 / 54(15 \%)$ cases with lymphoid neoplasms and 5/50 (10\%) control cases, class I discrepancies were found. This study shows the high rate of autopsy-verified lymphoid neoplasms and unrecognised comorbidities.
\end{abstract}

Keywords Autopsy $\cdot$ Post-mortem examination $\cdot$ Lymphoma $\cdot$ Plasmacytoma

\section{Introduction}

The diagnosis of lymphomas and plasmacytomas is a routine procedure during a patient's life time and there rarely is a demand for autopsy after patients have died. In case of severely ill patients, however, death may occur before a diagnosis has been established and autopsy can reveal previously unknown tumours and complications which led to death. It is well known that the rate of discrepancies between clinical diagnosis and autopsy findings is approximately 10-30\%. However, the rate of autopsies decreases constantly $[1,2]$. There are few systematic studies on autopsy-verified causes of death in patients with lymphoid neoplasms. Some studies are more than 25 years old and do not reflect modern diagnostic procedures and therapy options [3-6]. More recent studies seem to be biased by their inclusion criteria, e.g. a particular

Electronic supplementary material The online version of this article (https://doi.org/10.1007/s12308-019-00357-9) contains supplementary material, which is available to authorized users.

Kais Hussein

Hussein.Kais@MH-Hannover.de

1 Institute of Pathology, Hannover Medical School, Carl-Neuberg-Strasse 1, 30625 Hannover, Germany organ involvement or only post-transplant lymphoproliferative diseases (PTLD) [7-9]. Most of these studies have no control group without haematological neoplasms. The aim of the current study was to provide a more general characterisation. Thus, all types of lymphoid neoplasms as well as a control group were included. From our experience, autopsies are often rejected because the clinical diagnosis is "death due to lymphoma/plasmacytoma". By addressing clinically relevant questions, we intended to provide a rationale for initiating an autopsy, even if a lymphoid neoplasm had already been diagnosed. Therefore, the underlying study was designed to focus mainly on the cause of death and its association with the lymphoid neoplasm. A further objective was to analyse if certain subtypes of lymphoid neoplasms are more often diagnosed by autopsy than others. Finally, we aimed to evaluate the frequency of discrepancies of clinical and post-mortem diagnoses.

\section{Materials and methods}

\section{Study cohort}

Data was collected from autopsy reports from the archive of the Institute of Pathology at Hannover Medical School 
(MHH) within an arbitrary time interval (2006-2016). The retrospective study was approved by the local ethics committee (no. 2893-2015). Inclusion criteria $(n$ total $=104)$ : either present at autopsy or history of any lymphoid neoplasm $(n=$ $54 / 104)$. A control group without lymphoid neoplasms $(n=$ 50/104) was matched by age. Exclusion criteria for both were myeloid neoplasms.

Autopsies were performed in a standardised fashion [10] and included cranial, thoracic and abdominal preparations and macroscopic inspection. In all cases, heart, lungs, liver, spleen, gastrointestinal tract, kidneys and vertebral bone marrow were histologically evaluated (minimum of 15 tissue samples, haematoxylin and eosin as standard staining, Elastica van Gieson for lung tissues, periodic acid-Schiff for lung and kidney tissues, iron staining for lung, liver and spleen tissues, Giemsa for bone marrow tissues). In cases with tumour formation, bleeding or suspicious cervical/supraclavicular, paraaortal and inguinal lymphadenopathy $(>1 \mathrm{~cm})$, additional histology was applied. Immunohistochemistry and PCR were used if applicable.

\section{Analysis of data}

The following parameters were analysed: age, sex, body height, body and organ weights, pathological findings, type of lymphoid neoplasm, any other solid tumour, time between diagnosis of lymphoid neoplasm and death, immunosuppression/transplantation status and cause of death. We took into account that death is a multifactorial process which is influenced by different co-morbidities, therapy modalities and therapy durations in each individual patient. We re-evaluated all available clinical notes and subdivided all cases according to the most probable leading cause of death: failure of central nervous system, heart, lung, liver or kidney function, sepsis or haemorrhage/non-cardiac infarction. Sepsis was diagnosed only in cases with histologic septicopyaemic lesions. If more than one organ system was involved, the most severe pathologic condition was classified as the leading cause of death. Direct cause of death by the lymphoid neoplasm was defined as infiltration of tumour cells or amyloidosis in the organ with the leading failure of function.

For evaluation of the discrepancy between clinical diagnosis and autopsy findings, cases were grouped according to the Goldman criteria [11]: (i) class I error, misdiagnosis that may have affected survival and probably would have required alteration of treatment; (ii) class II error, misdiagnosis that did not affect survival and would not have required alteration of treatment; (iii) congruent or almost congruent clinical diagnosis and autopsy findings (including class III/IV errors, missed minor diagnoses unrelated to the disease course).

Statistical analyses of age and organ weights were performed with Prism 5.0 (GraphPad Software, San Diego, CA, USA).

\section{Results}

\section{Tumour subtypes and risk factors in patients with lymphoid neoplasms}

Lymphoid neoplasms were mainly B cell lymphomas (BNHL) and plasmacytomas and less often high-grade T-NHL and Hodgkin lymphomas (Table 1). Comparison of organ weights revealed no differences between the lymphoid neoplasm and control groups $(p>0.05)$.

In the lymphoid neoplasm group, 6/54 (11\%) had an infection with human immunodeficiency virus (HIV; $n=5 / 6$ highgrade B-NHL, $n=1 / 6$ plasmacytoma). In the control group, there was $1 / 50(2 \%)$ patient with HIV infection (Table 2).

In total, 4/54 (7\%) patients underwent transplantation before manifestation of a lymphoid neoplasm, but only three were classified as monomorphic PTLD (diffuse large B cell lymphomas after lung transplantation in two patients and bone marrow transplantation in a patient with aplastic anaemia). In one liver-transplanted patient, an Epstein-Barr virus (EBV)negative low-grade B-NHL manifested that was classified as incidental and not as monomorphic PTLD according to the WHO classification [12].

\section{Solid tumours}

In addition to lymphoid neoplasms, solid tumours manifested in $7 / 54$ (13\%) patients. Of these cases, $4 / 7$ had remission of carcinomas and 3/7 had tumours at autopsy, including two metastatic carcinomas and one unusual collusion tumour (HIV-positive patient with EBV-positive high-grade B-NHL in combination with an EBV-negative low grade smooth muscle actin-positive spindle cell tumour in the lung) (Table 1, Fig. 1).

In the control group, $12 / 50$ (24\%) cases had solid tumours: of these 4/12 with residual (apT3/4) or metastatic carcinomas at autopsy and the rest with an apT0 stage (Table 1).

\section{Frequency of clinically inapparent, suspected and known lymphoid neoplasms}

In the lymphoma cohort, a total of 10/54 (18\%) cases were primarily diagnosed by autopsy findings: high-grade B-NHL ( $n=6$; including 1/6 intravascular lymphoma), low-grade BNHL $(n=2)$, T-NHL $(n=1)$ and Hodgkin lymphoma $(n=1)$ (Table 1, Fig. 1).

In $15 / 54$ cases, a lymphoid neoplasm had been suspected shortly before death $(\leq 1$ month) and the diagnosis was verified by autopsy: high-grade B-NHL $(n=4$; including $1 / 4$ intravascular lymphoma), plasmacytomas ( $n=7 ; 3 / 7$ with clinically known amyloidosis) and T-NHL $(n=4)$. In one patient, a Hodgkin lymphoma was diagnosed one week before death in lymph node and spleen specimens, but no residual tumour 


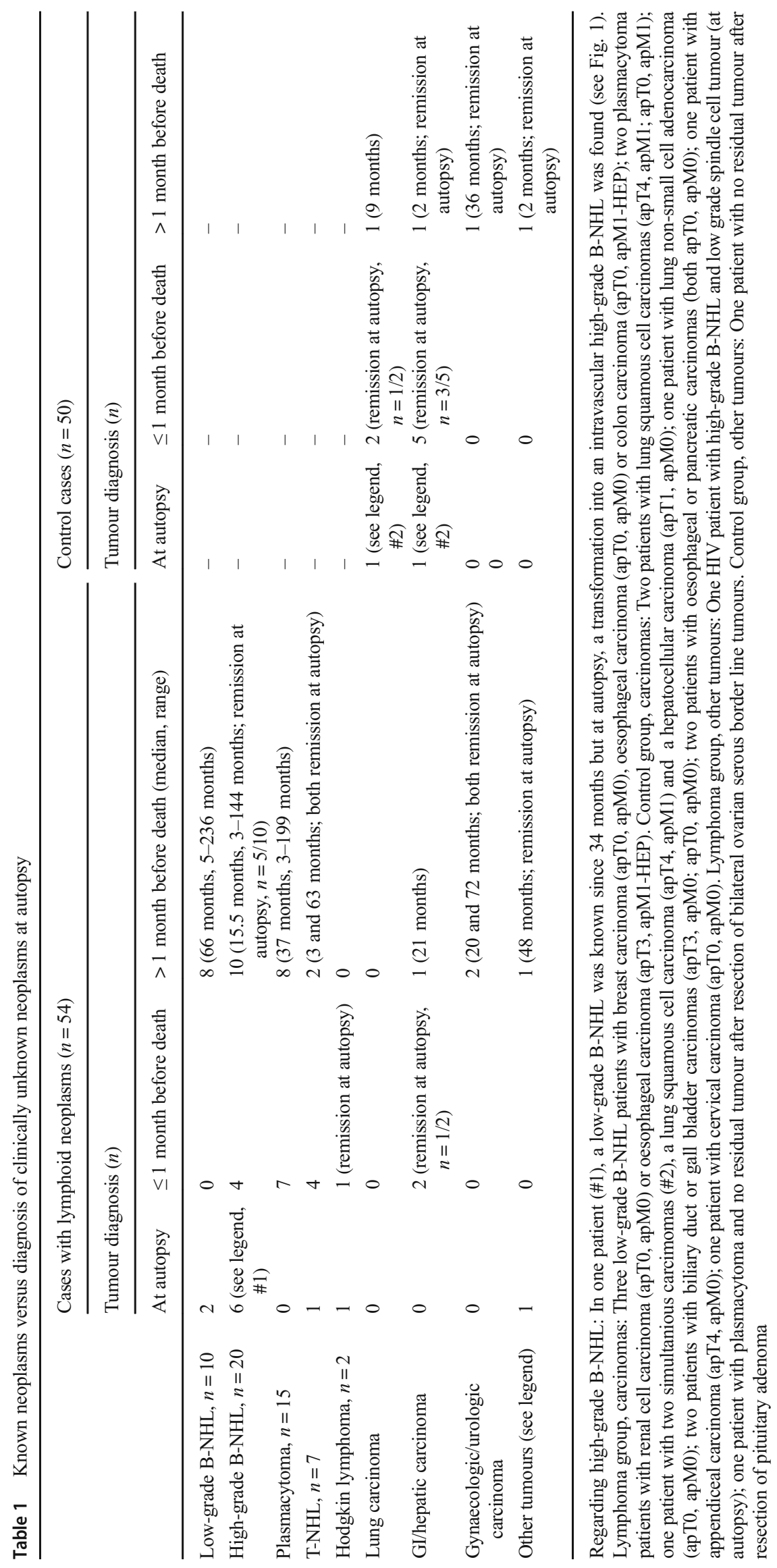


Table 2 Clinico-pathologic characteristics

\begin{tabular}{|c|c|c|}
\hline & $\begin{array}{l}\text { Cases with lymphoid } \\
\text { neoplasms }(n=54)\end{array}$ & $\begin{array}{l}\text { Control cases } \\
(n=50)\end{array}$ \\
\hline Sex (female/male) & $12 / 42(22 \% / 78 \%)$ & $16 / 34(32 \% / 68 \%)$ \\
\hline Age & $\begin{array}{l}\text { median } 57.5 \text { years } \\
\quad \text { (range } 24-84 \text { years) }\end{array}$ & $\begin{array}{l}\text { median } 61.5 \text { years } \\
\quad \text { (range } 31-82 \text { years) }\end{array}$ \\
\hline HIV (see legend) & $6 / 54(11 \%)$ & $1 / 50(2 \%)$ \\
\hline $\begin{array}{l}\text { Transplantation } \\
\text { before tumour }\end{array}$ & $4 / 54(7 \%)$ & $6 / 50(12 \%)$ \\
\hline $\begin{array}{l}\text { Tumour diagnosis at } \\
\text { autopsy }\end{array}$ & $10 / 54(18 \%)$ & $1 / 50(2 \%)$ \\
\hline $\begin{array}{l}\text { Tumour diagnosis } \\
\leq 1 \text { month } \\
\text { before death }\end{array}$ & $16 / 54(30 \%)$ & $7 / 50(14 \%)$ \\
\hline $\begin{array}{l}\text { Tumour diagnosis } \\
>1 \text { month before } \\
\text { death }\end{array}$ & $\begin{array}{c}\text { 28/54 (52\%; median } \\
37 \text { months, range } \\
\text { 3-236 months) }\end{array}$ & $\begin{array}{l}4 / 50(8 \% ; \text { median } \\
9 \text { months, range } \\
1.5 \text { months to } \\
\sim 3 \text { years })\end{array}$ \\
\hline
\end{tabular}

Lymphoid neoplasm group, virus infection: hepatitis $\mathrm{C}$ virus (HCV, $n=2$ / 54 , one with HIV coinfection), hepatitis B virus (HBV, $n=1 / 54$ ). Control group, virus infection: $\operatorname{HCV}(n=1 / 50), \operatorname{HBV}(n=1 / 50$ with HIV coinfection)

was found at autopsy. Therefore, the frequency of tumour diagnosis $\leq 1$ month before death was $30 \%(n=16 / 54)$.

In $28 / 54(52 \%)$ cases, the lymphoid neoplasms were known for $>1$ month (median 37 months, range 3-236 months): highgrade B-NHL ( $n=10$; including previously diagnosed lowgrade B-NHL with secondary transformation into a intravascular high-grade B-NHL, which was verified at autopsy), lowgrade B-NHL ( $n=8 ; 2 / 8$ with clinically known amyloidosis), plasmacytomas $(n=8)$ and T-NHL $(n=2)$.

In the previously mentioned case of a HIV patient, in addition to a high-grade B-NHL, a previously unknown low grade spindle cell tumour was diagnosed at autopsy $(n=1 /$ $54,2 \%$ ), whilst the other six solid tumours were known for a median of 20.5 months (range $<1-72$ months) before death.

In control cases, $1 / 50(2 \%)$ previously unknown metastatic lung carcinoma (apT4, apM1) with simultaneous hepatocellular carcinoma (apT1, apM0) was found at autopsy (clinically suspected pneumonia). The other 11 tumours were known for median $<1$ month (range $<1$ month to $\sim 3$ years; $n=9 / 11$ died within $\leq 2$ months after oncological surgical procedure) (Table 1). One patient without a tumour had a known AA type amyloidosis.

\section{Treatment and remission status in patients with known lymphoid neoplasms}

A specific therapy was applied in 20/54 patients with lymphoid neoplasms. In 3/20 patients with lymphoid neoplasm diagnosed shortly before death ( $\leq 1$ month), chemotherapy had been initiated. In 17/20 cases with lymphoid neoplasm diagnosed $>1$ month, rituximab with chemotherapy or chemotherapy alone had been administered. In 4/17 of these patients, stem cell transplantation had been performed. In eight patients, no residual lymphoid neoplasms were detectable at autopsy (5/8 high-grade B-NHL, 2/8 T-NHL, 1/8 Hodgkin lymphoma).

\section{Correlation of cause of death with lymphoma localisation}

The most frequent cause of death was cardiac/respiratory failure for the lymphoid neoplasm group $(n=35 / 54,65 \%)$ as well as for the control group ( $n=36 / 50,72 \%$ ) (Table 3 ).

In the lymphoma group, patients with cardiac failure $(n=$ 20 ) included $3 / 20$ cases with cardiac lymphoma manifestation (two intravascular high-grade B-NHL and one T-NHL) and 3/ 20 with cardiac amyloidosis. In $3 / 15$ cases with respiratory failure, lymphoid tumour cells infiltrated the lungs. Additional characteristics regarding organ failure and lymphoid tumour cell infiltration are shown in supplementary table 1 .

\section{Discrepancy between clinical diagnoses and autopsy findings}

Within the lymphoma group and the control cohort, clinical diagnoses were congruent to the autopsy findings in $21 / 54$ (39\%) and $26 / 50$ (52\%) of cases, respectively.

In 25/54 (46\%) patients with lymphoid neoplasms and 19/50 (38\%) control cases, class II discrepancies were noted.

In $8 / 54(15 \%)$ cases with lymphoid neoplasms and 5/50 (10\%) control cases, class I discrepancies were found. In the lymphoma group, these consisted of four high-grade B-NHL and each one low-grade B-NHL, plasmacytoma, T-NHL and Hodgkin lymphoma case (Table 3; supplementary table 2).

\section{Discussion}

In $18 \%$ of the study group, autopsy alone identified the clinically unknown or suspected lymphoid neoplasm, whilst only $2 \%$ of previously unknown solid tumours were found primarily by autopsy. It would be expected that indolent low-grade lymphomas are more frequently found as a coincidental disease in autopsies and that organ weights of liver and spleen are higher in patients with lymphomas. In contrast to this, few cases with low-grade lymphomas were newly diagnosed post-mortem and control cases had similar organ weights. Among the 26/54 patients who died shortly before further diagnostic evaluation could be performed or succumbed shortly after diagnosis within $\leq 1$ month, we noted that $58 \%$ ( $n=$ $15 / 26$ ) suffered from high-grade B- or T-NHL. This is concordant to another recently published study (supplementary table 3) [13]. It could be possible that in those cases, a higher 

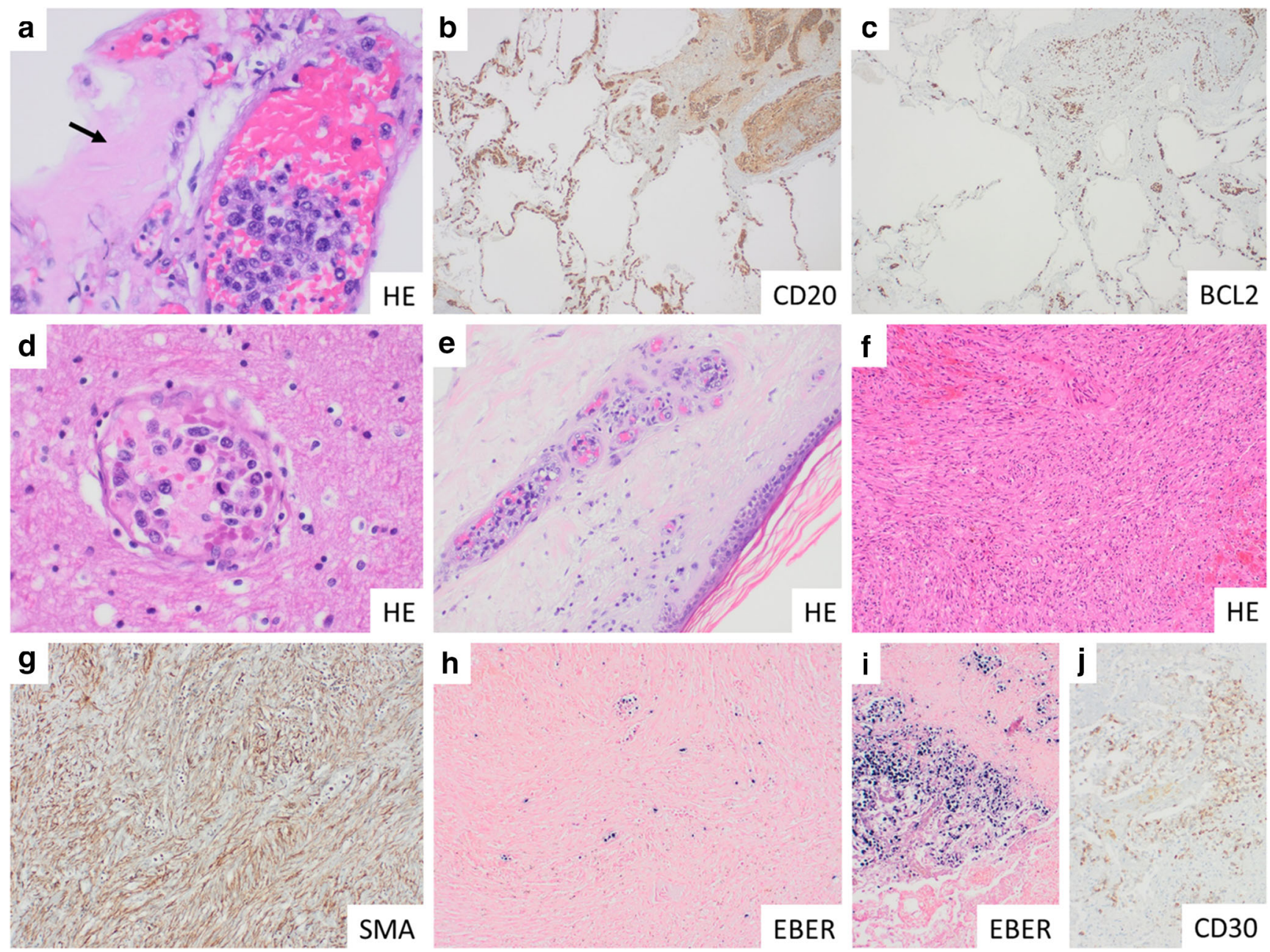

Fig. 1 Previously unknown tumours, diagnosed at autopsy. a-e In this patient, a B-CLL was known since 34 months, and short before death, a tuberculosis was suspected. Autopsy revealed no residual low-grade BNHL and no pneumonia but a rare intravascular high-grade B-NHL. Intravascular manifestation in the lungs was associated with acute alveolar oedema (arrow), which indicated acute left ventricular cardiac failure (a) magnification $\times 400)$. Tumour cells co-expressed CD20 (b; $\times 40)$, BCL2 $(\mathbf{c} ; \times 40)$, partially CD5, partially BCL6 and were negative for CD23 and EBER. In addition, intravascular tumour cells were found in the brain $(\mathbf{d} ; \times 400)$, skin $(\mathbf{e} ; \times 100)$, gut and kidneys. Note the typical lack of extravascular tumour cell infiltration in all images. $\mathbf{f}-\mathbf{j}$ In a HIV patient,

demand for initiating an autopsy was seen in order to clarify the cause of rapid deterioration.

In two recent studies on autopsy findings in lymphoma patients, respiratory failure manifested often ( $n$ total $=52 / 63,83 \%$; supplementary table 3) $[13,14]$. Comparison of autopsy findings in patients with lymphomas or acute myeloid leukaemias revealed no major differences; acute respiratory failure manifested in $88 \%$ and $85 \%$ of cases, respectively [14]. The majority of cases with clinical diagnosis of acute respiratory failure had autopsy-verified lung lesions such as pneumonia ( $40-45 \%)$, tumour infiltration $(\sim 20-25 \%)$ and thromboembolism $(\sim 10-15 \%)$ [14]. However, some had a high-grade B-NHL was known since 4 months and the patient succumbed to mycobacterial sepsis with septic lesions in bone marrow and spleen. A previously unknown pulmonary low grade mesenchymal spindle tumour was diagnosed at autopsy $(\mathbf{f} ; \times 40)$. Due to autolytic changes, further subclassification was limited, but spindle cells were positive for smooth muscle actin $(\mathrm{g} ; \times 40)$ and negative for caldesmon, desmin, CD34, CD31 and EBER $(\mathbf{h} ; \times 40)$. At the edge of the spindle cell tumour, the high-grade $\mathrm{B}$ cell lymphoma manifested, which was positive for EBER $(\mathbf{i} ; \times 40)$, CD30 $(\mathbf{j} ; \times 40)$ and lambda, but negative for CD20. Note the intermingled EBER+ lymphoma cells between the spindle cells in image $\mathbf{h}$

myocardiac lesions, such as cardiac tumour cell infiltration $(\sim 10 \%)$ [14]. In our cohort, pneumonia was the main cause of lung damage, both in lymphoma and non-lymphoma cases with respiratory failure. Several decades ago, two autopsy studies showed that infections are the main cause of death for patients with several subtypes of lymphoid neoplasms ( $n$ total $=121 / 246$, 49\%) [5, 15]. In another study, which included 156 autopsies from solid organ-transplanted patients and PTLD manifestation, infection was the cause of death in $41 \%$ of cases [9]. These included bronchopneumonia, aspergillosis and gastrointestinal infections but few cases with sepsis (4\%) [9]. In our cohort, septic 
inflammation was relatively rare, too. It has to be taken into consideration that sepsis is a relatively common clinical diagnosis in severely ill patients and that these patients are usually treated accordingly. We restricted the diagnosis of sepsis as the leading cause of death to those cases with septicopyogenic lesions at autopsy. Regarding sepsis, sepsis-like clinical presentation can be masked by a previously unknown lymphoma [16].

It can be assumed that the decrease of autopsies is caused by different factors. Many clinicians do not see the need for autopsies or are afraid that treatment errors could be detected retrospectively [17-21]. The misunderstanding regarding the role of non-legal autopsy is that it serves not to find treatment errors but to clarify which major co-morbidities manifested and to correlate clinical findings with autopsy findings. Based on previous autopsy studies, a general rate of class I discrepancies of $2-20 \%$ has to be expected [17-21]. In cases with lymphoid neoplasms, we found a rate of $15 \%$ $(n=8 / 54)$. In a recent autopsy study with a similar number of lymphoma cases, the rate of class I discrepancies was higher $(25 \% ; n=12 / 48)$ [14]. In some instances advanced disease stages and co-morbidities could be major factors that make diagnoses and differential diagnoses of lymphoid neoplasms difficult during life time. One reason for missing a relevant diagnosis could be that organ biopsies during life time may not have been performed if the risk of complications appeared to be unreasonably high. In addition, biopsies may be nondiagnostic. As discussed by van de Louw et al., the diagnostic yield of lung biopsies could be up to $80 \%$ but has to be balanced with a complication rate of up to $30 \%$ [14]. Another diagnostic difficulty is manifestation of extremely rare lymphoid neoplasms, e.g. intravascular high-grade B-NHL [22]. The characteristic pattern of intravascular infiltration, which usually lacks tissue infiltration, can be misinterpreted or overlooked, particularly in small biopsies [22]. Intravascular lymphoma cells can lead to increased intravascular obstructions and consecutive cardiopulmonary stress, which can mimic many other neurologic, dermatologic and cardiopulmonary diseases, e.g. respiratory distress [22]. In general, a considerable number of patients with intravascular lymphomas are diagnosed post-mortem by autopsy [22] and all three cases in our cohort were diagnosed at autopsy or shortly before death.

Whilst misdiagnosis may have lead to alteration of therapy, it has to be considered that not all patients may have benefited from this. In patients who are severely ill, it is questionable if modification of therapy would generally be applicable and effective. In addition, therapies have particular side effects which may be fatal, e.g. post-therapy bowel perforation after anti-lymphoma therapy [23]. Another example is the rare 
manifestation of an intravascular lymphoma, which generally has a poor prognosis even after ante-mortem diagnosis and therapy [22]. On the one hand, this shows that autopsy can identify class I errors. On the other hand, this does not mandatorily imply a long-lasting survival if the diagnosis was established during a patient's life time.

In summary, the rationale for initiating an autopsy in patients with suspected lymphoid neoplasms is the relatively high rate of post-mortem-identified diagnoses. Most patients succumbed to complications that were not directly related to the lymphoid neoplasm, and high-grade lymphomas are more often diagnosed shortly before or after death via autopsy than other lymphoid neoplasms. The frequency of class I discrepancies between clinical diagnosis and autopsy findings was $15 \%$ in our cohort, which is within the range of previously reported autopsy studies.

Acknowledgements The authors thank Mr. Karim Hussain and Mr. Martin Hill for editing the manuscript.

Contributions LA and KH conceived and designed the study. LA collected data and reviewed the literature. LA and $\mathrm{KH}$ analysed data. LA, HK and $\mathrm{KH}$ wrote, edited and reviewed the manuscript. All authors gave final approval for publication. $\mathrm{KH}$ takes full responsibility for the work as a whole, including the study design, access to data and the decision to submit and publish the manuscript.

\section{Compliance with ethical standards}

Retrospective evaluation of archived tissues and related data (ethics committee, MHH, no. 2893-2015).

Conflict of interest The authors declare that they have no conflict of interest.

\section{References}

1. Xavier AC, Siqueira SA, Costa LJ, Mauad T, Nascimento Saldiva PH (2005) Missed diagnosis in hematological patients-an autopsy study. Virchows Arch 446:225-231. https://doi.org/10.1007/ s00428-004-1186-y

2. Ozretić L, Schwindowski A, Dienes HP, Büttner R, Drebber U, Fries JWU (2017) Consequences of autopsies for the living: causes of death in the clinical diagnosis "septic and toxic shock". Pathologe 38:370-379. https://doi.org/10.1007/s00292-017-0305$\mathrm{x}$

3. Bank PM, Arseneau JC, Gralnick HR, Canellos GP, DeVita VT Jr, Berard CW (1975) American Burkitt's lymphoma: a clinicopathologic study of 30 cases. II. Pathologic correlations. Am J Med 58: 322-329

4. Feld R, Bodey GP, Rodriguez V, Luna M (1974) Causes of death in patients with malignant lymphoma. Am J Med Sci 268:97-106

5. Barcos M, Lane W, Gomez GA, Han T, Freeman A, Preisler H, Henderson E (1987) An autopsy study of 1206 acute and chronic leukemias (1958 to 1982). Cancer 60:827-837. https://doi.org/10.
$1002 / 1097-0142(19870815) 60: 4<827:$ : A ID CNCR2820600419>3.0.CO;2-A

6. Suzumiya J, Marutsuka K, Nabeshima K, Nawa Y, Koono M, Tamura K, Kimura N, Hisano S, Tachibana N, Inoue S et al (1993) Autopsy findings in 47 cases of adult T-cell leukemia/ lymphoma in Miyazaki prefecture. Japan Leuk Lymphoma 11: 281-286

7. Chinen K, Izumo T (2005) Cardiac involvement by malignant lymphoma: a clinicopathologic study of 25 autopsy cases based on the WHO classification. Ann Hematol 84:498-505. https://doi.org/10. 1007/s00277-005-1009-5

8. Costa H, Franco M, Hahn MD (2006) Primary lymphoma of the central nervous system: a clinical-pathological and immunohistochemical study of ten autopsy cases. Arq Neuropsiquiatr 64:976982. https://doi.org/10.1590/S0004-282X2006000600017

9. Sanromán Budiño B, Vázquez Martul E, Pértega Díaz S, Veiga Barreiro A, Carro Rey E, Mosquera Reboredo J (2004) Autopsydetermined causes of death in solid organ transplant recipients. Transplant Proc 36:787-789

10. Wittekind C (2017) S1-Leitlinie zur Durchführung von Obduktionen in der Pathologie des Bundesverbandes Deutscher Pathologen und der Deutschen Gesellschaft für Pathologie, 3. Aufl. Leitlinien Pathologie. (Hrsg. Bundesverband Deutscher Pathologen e. V. und Deutsche Gesellschaft für Pathologie e. V.)

11. Goldman L, Sayson R, Robbins S, Cohn LH, Bettmann M, Weisberg M (1983) The value of the autopsy in three medical eras. N Engl J Med 308:1000-1005. https://doi.org/10.1056/ NEJM198304283081704

12. Swerdlow SH, Campo E, Harris NL, Jaffe ES, Pileri SA, Stein H, Thiele J, Arber DA, Hasserjian RP, Le Beau MM, Orazi A, Siebert R (2017) World Health Organization classification of tumours of hematopoietic and lymphoid tissues. World Health Organization, Genf

13. Alkhasawneh A, Mubeen A, Gopinath A (2018) Lymphoma in autopsy cases. Forensic Sci Med Pathol 14:327-331. https://doi. org/10.1007/s12024-018-9996-4

14. Van de Louw A, Lewis AM, Yang Z (2019) Autopsy findings in patients with acute myeloid leukemia and non-Hodgkin lymphoma in the modern era: a focus on lung pathology and acute respiratory failure. Ann Hematol 98:119-129. https://doi.org/10.1007/s00277018-3494-3

15. Provencio M, España P, Salas C, Navarro F, Bonilla F (2000) Hogdkin's disease: correlation between causes of death at autopsy and clinical diagnosis. Ann Oncol 11:59-64. https://doi.org/10. 1023/A:1008396826812

16. Saraf SR, Naphade NS, Kalgutkar AD (2016) An analysis of autopsy cases of non-Hodgkin lymphoma-with special reference to those masquerading as acute febrile illness. J Cancer Res Ther 12: 763-764. https://doi.org/10.4103/0973-1482.158028

17. Marshall HS, Milikowski C (2017) Comparison of clinical diagnoses and autopsy findings: six-year retrospective study. Arch Pathol Lab Med 141:1262-1266. https://doi.org/10. 5858/arpa.2016-0488-OA

18. Schwanda-Burger S, Moch H, Muntwyler J, Salomon F (2012) Diagnostic errors in the new millennium: a follow-up autopsy study. Mod Pathol 25:777-783. https://doi.org/10.1038/ modpathol.2011.199

19. Wittekind C, Gradistanac T (2018) Post-mortem examination as a quality improvement instrument. Dtsch Arztebl Int 115:653-658. https://doi.org/10.3238/arztebl.2018.0653

20. Shojania KG, Burton EC, McDonald KM, Goldman L (2003) Changes in rates of autopsy-detected diagnostic errors over time: a systematic review. JAMA 289:2849-2856. https://doi.org/10. 1001/jama.289.21.2849

21. Seftel MD, Ho M, Pruthi D, Orbanski S, Rubinger M, Schacter B, Szwajcer D, Bredeson C, Demers AA (2007) High rate of 
discordance between clinical and autopsy diagnoses in blood and marrow transplantation. Bone Marrow Transplant 40:1049-1053. https://doi.org/10.1038/sj.bmt.1705855

22. Abraham L, Kreipe H, Raab P, Hussein K (2018) Clinical and pathological characteristics of intravascular lymphomas. Pathologe 39: 242-248. https://doi.org/10.1007/s00292-018-0427-9

23. Tai CC, Curtis JL, Szmuszkovicz JR, Horn MV, Ford HR, Woo MS, Wang KS (2008) Abdominal involvement in pediatric heart and lung transplant recipients with posttransplant lymphoproliferative disease increases the risk of mortality. J Pediatr Surg 43:2174-2177. https://doi.org/10.1016/j.jpedsurg. 2008.08.044

Publisher's note Springer Nature remains neutral with regard to jurisdictional claims in published maps and institutional affiliations. 